\title{
Inherent relations between yield stress and stability of bubble petroleum coke water slurry
}

\author{
Fu-Yan Gao ${ }^{1}$ - Eric J. $\mathrm{Hu}^{2}$
}

Received: 28 April 2017 / Published online: 7 February 2018

(C) The Author(s) 2018. This article is an open access publication

\begin{abstract}
The stability of petroleum coke water slurry (PCWS) is currently a hot topic. The inherent relationship between yield stress and stability of bubble-PCWS was studied through orthogonal experiments and range analysis in this work. The results showed that the stability of bubble-PCWS was positively related to the yield stress and that the yield stress could be greatly impacted by the operation conditions during preparation of bubble-PCWS. The main factors affecting the yield stress of bubble-PCWS were solid concentration, aeration time and dosage of frother. However, the effects of aperture size of air distribution plates and type of frother on the yield stress were slight within the experimental range. The optimal conditions for the greatest yield stress were as follows: aeration time of $30 \mathrm{~min}$, solid concentration of $65 \mathrm{wt} \%$, frother dosage of $0.030 \mathrm{wt} \%$ of the air-dried pulverized petroleum coke, aperture size of air distribution plate of 2-5 $\mu \mathrm{m}$ and AOS frother. The yield stress and the pour rate of bubble-PCWS under this optimum operation condition could reach maxima of more than $0.4 \mathrm{~Pa}$ and $96 \%$, respectively.
\end{abstract}

Keywords Petroleum coke $\cdot$ Petroleum coke water slurry (PCWS) - Stability $\cdot$ Yield stress $\cdot$ Orthogonal experiment

\section{Introduction}

Petroleum coke, an end product of the petroleum refining process, generally possesses high carbon content and shows good slurry ability for petroleum coke water slurry (PCWS) (Wang et al. 2012; He et al. 2011; Gao et al. 2010). PCWS usually has high calorific value and similar flow characteristics to oil, and may become a favorable substitute for fuel-oil (Gao et al. 2012, 2016). But the development and application of PCWS are restricted by its inferior stability (Wang et al. 2012; Zhan et al. 2010; Liu et al. 2013; Ma et al. 2013). A new solution, bubble-PCWS, which can make PCWS obtain both a high mass concentration and a good stability, has been presented (Gao et al. 2014). In the bubble-PCWS, bubble-particle complexes can be formed

Edited by Xiu-Qin Zhu

Fu-Yan Gao

gaofuyan@nit.zju.edu.cn

1 Ningbo Institute of Technology, Zhejiang University, Ningbo 315100, People's Republic of China

2 School of Mechanical Engineering, The University of Adelaide, Adelaide, SA 5005, Australia because of adsorption interaction at the bubble-particle phase boundary (Yianatos et al. 2008; Polat and Chander 2000; Mathe et al. 1998; Contreras et al. 2013; Zheng et al. 2004). And the three-dimensional network structures based on the bubble-particle complexes can effectively make the bubble-PCWS show ideal stability (Gao et al. 2014). That is to say, the stability of the bubble-PCWS has a direct relationship with the stability of three-dimensional network structures of the slurry.

Yield stress is the minimum stress that the slurry needs to overcome to start flowing when sheared. When the shear stress applied is not big enough to overcome the yield stress, the slurry will not flow. The yield stress is directly related to the three-dimensional network structure of the slurry and can represent the strength of the network structure to some extent. Therefore, there must be some kind of internal relations between the yield stress and the stability of bubble-PCWS. In order to comprehensively examine this relationship between them, orthogonal experiments and range analysis have been done in this paper. Five factors (i.e., solid concentration, aeration time, aperture size of air distribution plate, dosage and type of frother) were considered while preparing bubble-PCWS. Orthogonality means that all lever values of each factor are 
symmetric and orthogonal to each other and that the levers of all factors are assembled uniformly to arrange operation conditions without omissions and repetitions (Liu 2006). The orthogonal experiments can not only obtain much more information, but also reduce the experimental workload.

\section{Experimental}

\subsection{Materials}

A petroleum coke from Jinshan Petrochemical Co. Ltd. was used in the experiments. The proximate and ultimate analysis results of the petroleum coke sample are shown in Table 1. The molecular formula of the petroleum coke can be drawn from the ultimate analysis results in Table 1, which turns out to be ' $\mathrm{C}_{106} \mathrm{H}_{51} \mathrm{NSO}_{4}$.'

The dispersing agent used was sodium lignosulfonate at a concentration of $0.8 \mathrm{wt} \%$ of the air-dried pulverized petroleum coke, which could optimize the slurryability of PCWS (Gao et al. 2015). Two types of anionic surface active agents, sodium lauryl sulfate (K12) and $\alpha$-olefin sulfonate (AOS), were used as frothers. Frothers with amphiphilic molecular structure are adsorbed and aligned at the liquid-vapor interface. This produces a reduction in the liquid-gas surface tension and system energy, which causes air to disperse in the slurry to form bubbles of smaller diameter (Zhao et al. 2012).

\subsection{Equipment and methods}

\subsubsection{Preparation of bubble-PCWS}

Figure 1 shows a flowchart of the process for preparing bubble-PCWS. The petroleum coke was ground in a ball mill to obtain pulverized samples, and particles below 100 mesh were selected by an electric sieve shaker. The petroleum coke particles, deionized water, dispersing agent and frother were mixed with an electric mixer at $1000 \mathrm{r} /$ min for 10 min forming an initial bubble-PCWS. The initial bubble-PCWS was put into a container with an air distribution plate. Subsequently, compressed air (0.7 MPa, $1.5 \mathrm{~m}^{3} / \mathrm{h}$ ) was blown into the container from the bottom of the container through the air distribution plate. The samples of bubble-PCWS were obtained after a certain amount of compressed-air blow time. The compressed air was produced by an air compressor and was measured by a pressure gauge and a flow meter. In addition, a thermostatic bath set to $20{ }^{\circ} \mathrm{C}$ was used to avoid the effect of variation in compressed air temperature on the nature of the slurry.

\subsubsection{Determination of granularity distribution}

Granularity distribution of the selected petroleum coke powder was measured with a British Mastersizer (2000) laser particle size instrument, as shown in Fig. 2. And the average diameter of petroleum coke particles was about $27 \mu \mathrm{m}$.

\subsubsection{Determination of yield stress}

The yield stress values were obtained by fitting the shear stress-shear rate curve using Herschel-Bulkley models. Both shear stress and shear rate were measured on a rotary viscometer (NXS-4C, Thermo, China). Three-parameter Herschel-Bulkley models are described as Eq. (1) (Ma et al. 2013).

$$
\begin{cases}\dot{\gamma}=0 & \tau \leq \tau_{y} \\ \tau=\tau_{y}+k \dot{\gamma}^{n} & \tau>\tau_{y}\end{cases}
$$

where $\dot{\gamma}$ is the shear rate, $\mathrm{s}^{-1}$; $\tau$ the shear stress, $\mathrm{Pa} ; \tau_{y}$ the yield stress $(\mathrm{Pa}) ; k$ the consistency coefficient, $\mathrm{Pa}$ sn; $n$ the dimensionless flow characteristic exponent.

\subsubsection{Determination of stability}

The stability of bubble-PCWS was measured by an inversion method. The measurement started by keeping the slurry in a sealed container for 7 days. Then, the container was tilted for $30 \mathrm{~s}$ to make the slurry flow out freely and then, inverted vertically for $8 \mathrm{~min}$. Finally, we weighed and calculated the mass of poured slurry, and used the pour rate and the ratio of poured mass to the total mass of slurry as indicators to evaluate slurry stability. A higher pour rate indicates a more stable slurry.
Table 1 Proximate and ultimate analysis results of the petroleum coke

\begin{tabular}{|c|c|c|c|c|c|c|c|c|c|}
\hline \multicolumn{4}{|c|}{ Proximate analysis, wt $\%$} & \multirow{2}{*}{$\begin{array}{l}Q_{\mathrm{b}, \mathrm{ad}} \\
\mathrm{kJ} \mathrm{kg}^{-1}\end{array}$} & \multicolumn{5}{|c|}{ Ultimate analysis, wt $\%$} \\
\hline $\mathrm{M}_{\mathrm{ad}}$ & $\mathrm{A}_{\mathrm{ad}}$ & $\mathrm{V}_{\mathrm{ad}}$ & $\mathrm{FC}_{\mathrm{ad}}$ & & $\mathrm{C}_{\mathrm{ad}}$ & $\mathrm{H}_{\mathrm{ad}}$ & $\mathrm{N}_{\mathrm{ad}}$ & $\mathrm{St}_{\mathrm{ad}}$ & $\mathrm{O}_{\mathrm{ad}}$ \\
\hline 1.07 & 0.73 & 10.0 & 88.2 & 35,461 & 88.77 & 3.55 & 1.01 & 2.22 & 4.45 \\
\hline
\end{tabular}

Subscript ad stands for air-dried basis; M, A, V and FC stand for moisture, ash, volatile and fixed carbon, respectively; $Q_{\mathrm{b}, \text { ad }}$ stands for the high heating value in air-dried basis; C, H, N, St and O stands for carbon, hydrogen, nitrogen, total sulfur and oxygen, respectively. The oxygen data are obtained by calculation 


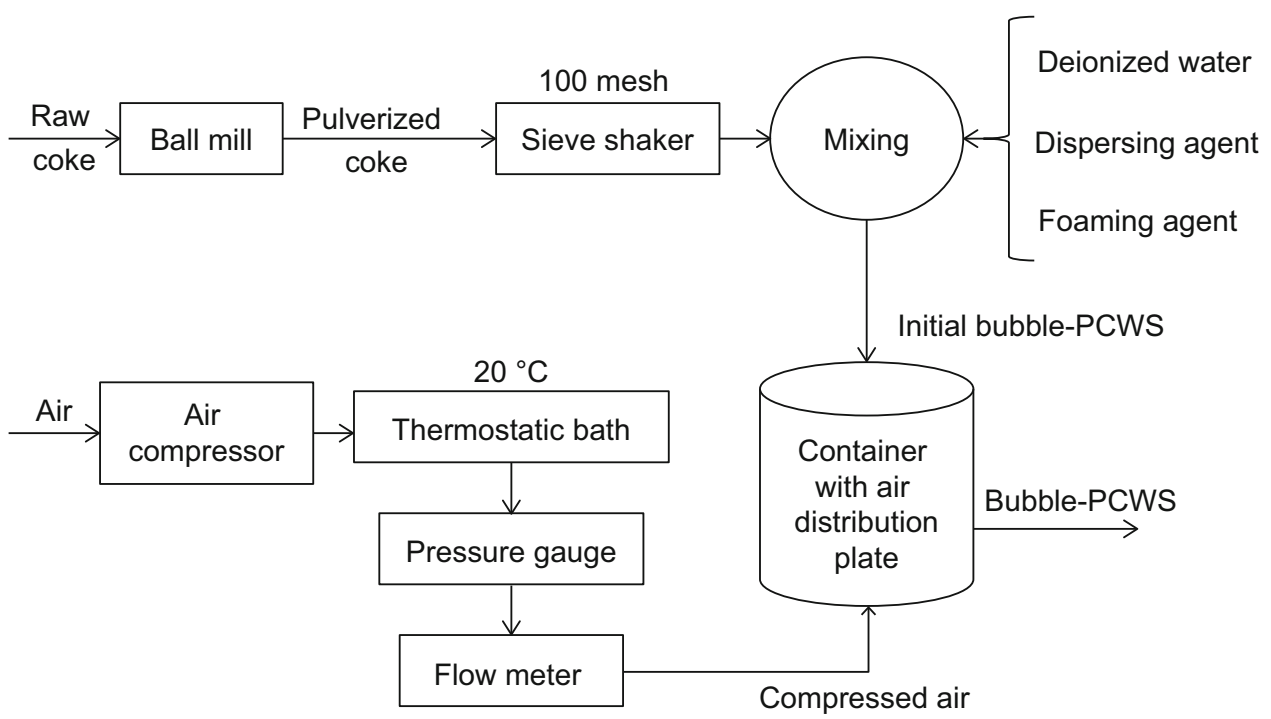

Fig. 1 Process flowchart for preparing bubble-PCWS

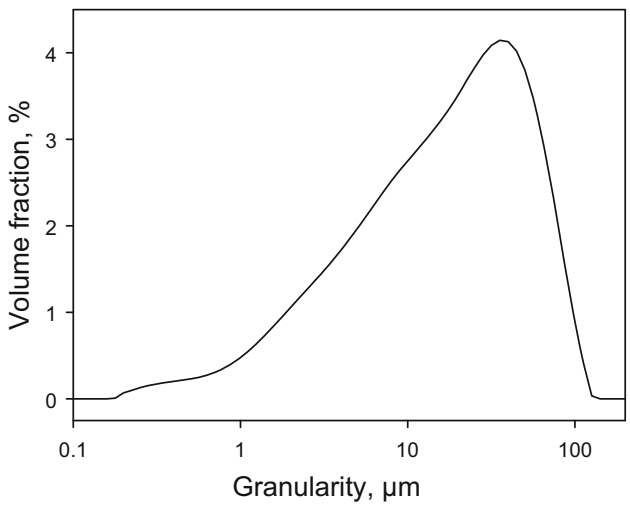

Fig. 2 Granularity distribution of petroleum coke powder

\subsection{Choice of levers of the factors in orthogonal experiments}

There were five factors (i.e., solid concentration, aeration time, aperture size of air distribution plate, dosage and type of frother) considered in the orthogonal experimental design, as shown in Table 2. The factor, type of frother, had two levers, and the other factors each possessed four levers. In order to simplify the experimental process, the interaction between various factors was not considered.

According to the results of single factor analysis (Gao et al. 2014), the ranges of operational parameters were arranged as follows. Solid concentration of slurry was set as $65 \%-68 \%$ and the aeration time as 0-30 min. Four different air distribution plate apertures were used in experiments, and aperture ranges were $40-80 \mu \mathrm{m}$, 15-40 $\mu \mathrm{m}, 5-15 \mu \mathrm{m}$ and $2-5 \mu \mathrm{m}$, respectively. Two types of frother, K12 and AOS, were used, respectively. The dosage of frother was at a concentration of $0-0.045 \mathrm{wt} \%$ of the air-dried pulverized petroleum coke.

\section{Results and discussion}

\subsection{Design and results of orthogonal experiments}

The orthogonal array (Liu 2006), $\mathrm{L}_{16}\left(4^{4} \times 2^{3}\right)$, was applied in this paper, and 16 operation conditions were chosen by assembling the levers of different factors, as shown in rank 2-6 in Table 3. Two repeated experiments were made on each operation condition. The orthogonal
Table 2 Factors and levers of bubble-PCWS in orthogonal experimental design

\begin{tabular}{lllllll}
\hline Factors & & & Lever 1 & Lever 2 & Lever 3 & Lever 4 \\
\hline Factor code & Factor name & Unit & & & & \\
\hline A & Solid concentration & $\%$ & 65 & 66 & 67 & 68 \\
B & Aeration time & min & 0 & 20 & 10 & 30 \\
C & Aperture size & $\mu \mathrm{m}$ & $5-15$ & $15-40$ & $40-80$ & $2-5$ \\
D & Dosage of frother & $\%$ & 0 & 0.030 & 0.015 & 0.045 \\
E & Type of frother & - & K12 & AOS & - & - \\
\hline
\end{tabular}


experimental results, the yield stress and the pour rate, are shown in rank 7-10 in Table 3. It can be seen from Table 3 that the operation conditions while preparing bubblePCWS greatly impacted the yield stress and the pour rate of slurry and that the pour rate was positively related to the yield stress. In fact, the yield stress is related to the stability of the space structure of bubble-PCWS. The more stable the space structure is, the greater the shear stress will be needed to overcome the high spatial structure resistance, and the bigger the yield stress shows. The bubble-PCWS with lower yield stress possesses lower initial viscosity and better liquidity, but its steric hindrance is weaker, and the particles are much easier to sink down and agglomerate during the storage, resulting in a lower pour rate and an inferior slurry stability.

\subsection{Range analysis of orthogonal experimental results}

Range analysis can be applied to the orthogonal experimental results to quantitatively analyze the integrated optimal levels of multiple factors and distinguish the primary and secondary influential factors on the yield stress. Range means the biggest difference between the experimental results at different levels of each factor. The bigger the range of one factor, the greater the effect of this factor on the yield stress (Liu 2006). For all levers of one factor, every lever of other factors appears equally because of orthogonality of the orthogonal array. Therefore, when one factor is studied, the other factors cannot be considered temporarily because their effects cancel each other out.
The number of operation conditions is marked as $n$, and the sequence number is $i, i=1 \sim n$. The same experiments are repeatedly made by $k$ times on every operation condition, and the sequence number of repeated experiments is $j, j=1 \sim k$. A single experimental result is marked as $y_{i j}$. The lever amount of a factor is $M$, and the sequence number of a lever is $r, r=1 \sim M$. The number of experiments on the same factor and same lever is $L$ in total, and the virtual sequence number is $q, q=1 \sim L$. The experimental result in lever $r$ of a factor is marked as $y_{r q}$, and then, the sum for each factor in each level, $\sum(r)$, is presented as Eq. (2).

$\sum(r)=\sum_{q=1}^{L} y_{r q}$

The average experimental result for each factor in each level, $k_{r}$, can be described by Eq. (3).

$k_{r=} \frac{\sum_{q=1}^{L} y_{r q}}{L}$

The indicator $k_{r}$ can accurately reflect the effective extent of a factor in lever $r$. The higher the value of $k_{r}$ is, the more beneficial the lever $r$ turns out to be to improve slurry yield stress. The optimal lever for the yield stress can be found by comparing $k_{r}$ on each lever of one factor, and the range $R$ can be calculated by Eq. (4).

$R=\max k_{r}-\min k_{r}$

The primary and secondary influential factors on the yield stress can be distinguished by comparing the range of
Table 3 Orthogonal experimental design and results of bubble-PCWS

\begin{tabular}{|c|c|c|c|c|c|c|c|c|c|}
\hline \multirow[t]{2}{*}{ Serial number } & \multirow{2}{*}{$\begin{array}{l}\text { Factor } \\
\text { A }\end{array}$} & \multirow{2}{*}{$\begin{array}{l}\text { Factor } \\
\text { B }\end{array}$} & \multirow{2}{*}{$\begin{array}{l}\text { Factor } \\
\text { C }\end{array}$} & \multirow{2}{*}{$\begin{array}{l}\text { Factor } \\
\text { D }\end{array}$} & \multirow{2}{*}{$\begin{array}{l}\text { Factor } \\
\text { E }\end{array}$} & \multicolumn{2}{|c|}{ Yield stress, Pa } & \multicolumn{2}{|c|}{ Pour rate, $\%$} \\
\hline & & & & & & 1 st test & 2nd test & $1 \mathrm{st}$ test & 2 nd test \\
\hline 1 & 65 & 0 & $5-15$ & 0.000 & K12 & 0.02 & 0.01 & 15.11 & 15.09 \\
\hline 2 & 65 & 20 & $15-40$ & 0.030 & K12 & 0.31 & 0.34 & 89.97 & 95.04 \\
\hline 3 & 65 & 10 & $40-80$ & 0.015 & AOS & 0.03 & 0.04 & 30.77 & 34.43 \\
\hline 4 & 65 & 30 & $2-5$ & 0.045 & AOS & 0.35 & 0.38 & 94.61 & 95.81 \\
\hline 5 & 66 & 0 & $15-40$ & 0.015 & AOS & 0.04 & 0.05 & 22.29 & 24.99 \\
\hline 6 & 66 & 20 & $5-15$ & 0.045 & AOS & 0.23 & 0.21 & 83.07 & 81.06 \\
\hline 7 & 66 & 10 & $2-5$ & 0.000 & K12 & 0.06 & 0.05 & 31.75 & 30.22 \\
\hline 8 & 66 & 30 & $40-80$ & 0.030 & K12 & 0.24 & 0.28 & 83.84 & 86.39 \\
\hline 9 & 67 & 0 & $40-80$ & 0.045 & K12 & 0.07 & 0.06 & 17.91 & 16.79 \\
\hline 10 & 67 & 20 & $2-5$ & 0.015 & K12 & 0.01 & 0.02 & 25.01 & 27.48 \\
\hline 11 & 67 & 10 & $5-15$ & 0.030 & AOS & 0.11 & 0.13 & 27.65 & 29.11 \\
\hline 12 & 67 & 30 & $15-40$ & 0.000 & AOS & 0.05 & 0.04 & 23.89 & 22.46 \\
\hline 13 & 68 & 0 & $2-5$ & 0.030 & AOS & 0.07 & 0.06 & 17.41 & 16.03 \\
\hline 14 & 68 & 20 & $40-80$ & 0.000 & AOS & 0.05 & 0.03 & 16.15 & 16.02 \\
\hline 15 & 68 & 10 & $15-40$ & 0.045 & K12 & 0.06 & 0.07 & 19.21 & 20.77 \\
\hline 16 & 68 & 30 & $5-15$ & 0.015 & K12 & 0.09 & 0.08 & 28.99 & 27.82 \\
\hline
\end{tabular}


Table 4 Range analysis of yield stress of bubble-PCWS in orthogonal experiments

\begin{tabular}{|c|c|c|c|c|c|}
\hline \multirow[t]{2}{*}{ Analysis indicators } & \multicolumn{5}{|c|}{ Yield stress, $\mathrm{Pa}$} \\
\hline & Factor A & Factor B & Factor $\mathrm{C}$ & Factor D & Factor E \\
\hline \multicolumn{6}{|c|}{ Sum for each factor in each level } \\
\hline$\Sigma 1$ & 1.48 & 0.38 & 0.88 & 0.31 & 1.77 \\
\hline$\Sigma 2$ & 1.16 & 1.20 & 0.96 & 1.54 & 1.87 \\
\hline$\Sigma 3$ & 0.49 & 0.55 & 0.80 & 0.36 & - \\
\hline$\Sigma 4$ & 0.51 & 1.51 & 1.00 & 1.43 & - \\
\hline \multicolumn{6}{|c|}{ Average for each factor in each level } \\
\hline$k_{1}$ & 0.19 & 0.05 & 0.11 & 0.04 & 0.11 \\
\hline$k_{2}$ & 0.15 & 0.15 & 0.12 & 0.19 & 0.12 \\
\hline$k_{3}$ & 0.06 & 0.07 & 0.10 & 0.05 & - \\
\hline$k_{4}$ & 0.06 & 0.19 & 0.13 & 0.18 & - \\
\hline Range $R$ & 0.13 & 0.14 & 0.03 & 0.15 & 0.01 \\
\hline Optimal lever & A1 & B4 & $\mathrm{C} 4$ & D2 & E2 \\
\hline Order of influential factors & \multicolumn{5}{|c|}{$\mathrm{D}>\mathrm{B}>\mathrm{A}>\mathrm{C}>\mathrm{E}$} \\
\hline
\end{tabular}

each factor. The results of range analysis of yield stress of bubble-PCWS are shown in Table 4.

It can be seen from Table 4 that the bubble-PCWS could obtain the biggest yield stress when the operational parameters were set as follows, aeration time of $30 \mathrm{~min}$, solid concentration of $65 \mathrm{wt} \%$, frother dosage of $0.030 \mathrm{wt} \%$ of the air-dried pulverized petroleum coke, aperture size of air distribution plate of $2-5 \mu \mathrm{m}$ and AOS frother. It can also be seen from the range values of the five factors in Table 4 that the main factors affecting the yield stress of bubble-PCWS were solid concentration, aeration time and frother dosage. However, the effects of aperture size of air distribution plate and type of frother on the yield stress were slight within the experimental range.

\subsection{Verification of orthogonal experimental results}

According to range analysis of orthogonal experimental results, the integrated optimal levels of multiple factors for the greatest yield stress were as follows, aeration time of $30 \mathrm{~min}$, solid concentration of $65 \mathrm{wt} \%$, frother dosage of $0.030 \mathrm{wt} \%$ of the air-dried pulverized petroleum coke, aperture size of air distribution plate of $2-5 \mu \mathrm{m}$ and AOS frother. However, this optimum operation condition was not included in the original experimental plan. Therefore, confirmatory tests under this optimum operation condition were necessary, and results are shown in Table 5.

It is shown from Table 5 that the yield stress and the pour rate of bubble-PCWS under these optimum operation conditions could, respectively, reach more than $0.4 \mathrm{~Pa}$ and $96 \%$, which were greater than all the results in the original
Table 5 Results of confirmatory tests on the optimal levels of multifactors

\begin{tabular}{lccc}
\hline Indicators & \multicolumn{3}{c}{ Under the optimum operation condition } \\
\cline { 2 - 4 } & 1st test & 2nd test & Average \\
\hline Yield stress, $\mathrm{Pa}$ & 0.407 & 0.415 & 0.411 \\
Pour rate, \% & 96.03 & 96.25 & 96.14 \\
Slurry density, $\mathrm{g} \mathrm{cm}^{-3}$ & 0.854 & 0.863 & 0.859 \\
Apparent viscosity, $\mathrm{mPa} \mathrm{s}$ & 575.0 & 637.0 & 606.0 \\
\hline
\end{tabular}

experimental plan. Hence, the combination condition with aeration time of $30 \mathrm{~min}$, solid concentration of $65 \mathrm{wt} \%$, frother dosage of $0.030 \mathrm{wt} \%$ of the air-dried pulverized petroleum coke, aperture size of air distribution plate of 2-5 $\mu \mathrm{m}$ and AOS frother was the integrated optimal levels of multiple factors for the greatest yield stress and the best stability within the experimental range. The apparent viscosity of bubble-PCWS is now around $600 \mathrm{mPa}$ s, which is appropriate for industrial application of the slurry.

\subsection{Effects of yield stress on bubble stability}

The stability of bubble-PCWS depends on the stability of bubbles in the slurry. Ignoring bubble gravity, bubbles are generally impacted by the buoyancy impelling bubbles to float up and the stress from slurry restraining bubble movements. It has been pointed out (Asmatulu 2008; Oshitani et al. 2012; Galvin et al. 2001; Sikorskia et al. 2009) that the bubbles are stably suspended in the slurry when the buoyancy was less than the yield stress of the slurry, and on the contrary, the bubbles rose out of slurry 
when the buoyancy was greater than the yield stress. On the basis of this theory, the precondition of stable suspension of bubbles in the slurry without rising had been obtained as Eq. (5).

$\tau_{\mathrm{y}}>\frac{\rho_{\mathrm{s}} g \cdot\left(\pi D^{3} / 6\right)}{\pi D^{2} / 4}$

where $\tau_{\mathrm{y}}$ is the yield stress, $\mathrm{Pa} ; \rho_{\mathrm{s}}$ the slurry density, $\mathrm{kg} / \mathrm{m}^{3}$; $g$ the acceleration of gravity, $\mathrm{m} / \mathrm{s}^{2} ; D$ the bubble diameter, $\mathrm{m}$.

Hence, the bubble diameter range of stable suspension can be calculated based on the value of yield stress, shown as Eq. (6).

$D<\frac{3 \tau_{\mathrm{y}}}{2 \rho_{\mathrm{s}} g}$

It can be seen from Eq. (6) that the critical diameter of stable suspended bubbles is directly proportional to the yield stress. The greater the yield stress is, the bigger the critical diameter of bubbles becomes. In other words, the diameter range of bubbles that can stably suspend in slurry increases with increasing yield stress. Therefore, the greater the yield stress is, the more bubbles there are in the stable suspension system to prevent sedimentation of particles, leading to a better slurry stability. This is identical with the above experimental result that the slurry stability was positively related to the yield stress.

\subsection{Effects of yield stress on particle stability}

The main force causing sedimentation of particles in slurry system is gravity. Settling stress from gravity is determined by particle mass, action area of gravity and density difference between particle and dispersion medium (Cosgrove 2009). Only when this settling stress is less than the yield stress of slurry can particles stay in suspension in the slurry. That is to say, the precondition of a stable suspension of particles in the slurry without settling is that the yield stress is greater than the settling stress, shown as Eq. (7).

$\tau_{\mathrm{y}}>\frac{4 \times \Delta \rho g a}{3}$

where $\Delta \rho$ the density difference between particle and dispersion medium, $\mathrm{kg} / \mathrm{m}^{3} ; a$ the particle radius, $\mathrm{m}$.

In the above orthogonal experiments, the average radius of petroleum coke particle was $13.5 \mu \mathrm{m}$, the true density of petroleum coke was $2140 \mathrm{~kg} / \mathrm{m}^{3}$, and the density of the dispersion medium was $1000 \mathrm{~kg} / \mathrm{m}^{3}$. Therefore, it can be calculated according to Eq. (6) that only when $\tau_{\mathrm{y}}>0.194 \mathrm{~Pa}$ could the bubble-PCWS have the possibility for possessing good stability within the experimental range. It can be seen from Tables 3 and 5 that the bubble-PCWS with yield stress being more than $0.194 \mathrm{~Pa}$ possessed better stability with pour rate being over $80 \%$, while the bubblePCWS with yield stress being less than $0.194 \mathrm{~Pa}$ possessed worse stability with pour rate being under $35 \%$. Hence, the experimental results were in conformity with the above theory that the slurry could possess much better stability when the yield stress was greater than the settling stress.

\section{Conclusions}

(1) Through orthogonal experiment design, it is clear that the operation conditions while preparing bubblePCWS greatly impacted the yield stress and the pour rate of slurry and that the pour rate was positively related to the yield stress.

(2) Through range analysis, the following conclusions can be drawn. The main factors affecting the yield stress of bubble-PCWS were solid concentration, aeration time and dosage of frother. However, the effects of aperture size of air distribution plate and type of frother on the yield stress were slight within the experimental range. The optimal levels of multiple factors for the greatest yield stress were as below, aeration time of $30 \mathrm{~min}$, solid concentration of $65 \mathrm{wt} \%$, frother dosage of $0.030 \mathrm{wt} \%$ of the airdried pulverized petroleum coke, aperture size of air distribution plate of 2-5 $\mu \mathrm{m}$ and AOS frother type. And on this occasion, the bubble-PCWS could possess the best stability within the experimental range. The yield stress and the pour rate of bubblePCWS under this optimum operation condition could reach more than $0.4 \mathrm{~Pa}$ and $96 \%$, respectively.

(3) The bigger the yield stress was, the better the slurry stability turned out to be, which could be interpreted from two aspects. On the one hand, the diameter range of bubbles that can steadily suspend in slurry increases with increasing yield stress, and there will be more bubbles in the stable suspension system to prevent sedimentation of particles. On the other hand, particles can steadily suspend in the slurry only when the yield stress is greater than the settling stress, which makes it possible that the slurry possesses good stability.

Acknowledgements The authors would like to acknowledge the financial supports from National Natural Science Foundation of China (Grant No. 51506185) and Zhejiang Provincial Natural Science Foundation of China (Grant No. LQ15E060002).

Open Access This article is distributed under the terms of the Creative Commons Attribution 4.0 International License (http://crea tivecommons.org/licenses/by/4.0/), which permits unrestricted use, distribution, and reproduction in any medium, provided you give 
appropriate credit to the original author(s) and the source, provide a link to the Creative Commons license, and indicate if changes were made.

\section{References}

Asmatulu R. Improving the dewetability characteristics of hydrophobic fine particles by air bubble entrapments. Powder Technol. 2008;186:184-8. https://doi.org/10.1016/j.powtec.2007.11.040.

Contreras F, Yianatos J, Vinnett L. On the froth transport modelling in industrial flotation cells. Miner Eng. 2013;41:17-24. https:// doi.org/10.1016/j.mineng.2012.10.016.

Cosgrove T. Colloid science. Beijing: Chemical Industry Publishing House; 2009. ISBN 9787122035004 (in Chinese).

Galvin KP, Pratten SJ, Shankar NG, et al. Production of high internal phase emulsions using rising air bubbles. Chem Eng Sci. 2001;56:6285-93. https://doi.org/10.1016/S0009-2509(01)002 93-7.

Gao FY, Hu EJ. Effects of $\mathrm{pH}$ on rheological characteristics and stability of petroleum coke water slurry. Pet Sci. 2016;13(4): 782-7. https://doi.org/10.1007/s12182-016-0118-1.

Gao FY, Jiang L, Zhang XZ. Experimental research of optimum additive dosage for petroleum coke water slurry. Chem Eng (China). 2015;43(5):63-7. https://doi.org/10.3969/j.issn.10059954.2015.05.014 (in Chinese).

Gao FY, Liu JZ, Wang CC, et al. Effects of the physical and chemical properties of petroleum coke on its slurryability. Pet Sci. 2012;2:251-6. https://doi.org/10.1007/s12182-012-0206-9.

Gao FY, Liu JZ, Wang CC, et al. The slurryability of petroleum coke and the rheological characteristics and stability of PCWS. J Chem Ind Eng (China). 2010;61(11):2912-8 (in Chinese).

Gao FY, Liu JZ, Zhou JH, et al. Preparation and improving stability of bubble petroleum coke water slurry. Fuel. 2014;128:404-9. https://doi.org/10.1016/j.fuel.2014.03.032.

He QH, Wang R, Wang WW, et al. Effect of particle size distribution of petroleum coke on the properties of petroleum coke-oil slurry. Fuel. 2011;90:2896-901. https://doi.org/10.1016/j.fuel.2011.03. 029.

Liu JT. Method of experimental study. Xuzhou: China University of Mining and Technology Press; 2006. ISBN 9787811073362 (in Chinese).
Liu M, Duan YF, Li HF. Effect of modified sludge on the rheological properties and co-slurry mechanism of petroleum coke-sludge slurry. Powder Technol. 2013;243:18-26. https://doi.org/10. 1016/j.powtec.2013.03.036.

Ma XY, Duan YF, Liu M. Effects of petrochemical sludge on the slurry-ability of coke water slurry. Exp Therm Fluid Sci. 2013;48:238-44. https://doi.org/10.1016/j.expthermflusci.2013. 03.006 .

Mathe ZT, Harris MC, O'Connor CT, et al. Review of froth modelling in steady state flotation systems. Miner Eng. 1998;11:397-421. https://doi.org/10.1016/S0892-6875(98)000 20-X.

Oshitani J, Isei YH, Yoshida M, et al. Influence of air bubble size on float-sink of spheres in a gas-solid fluidized bed. Adv Powder Technol. 2012;23:120-3. https://doi.org/10.1016/j.apt.2011.08. 002.

Polat M, Chander S. First-order flotation kinetics models and methods for estimation of the true distribution of flotation rate constants. Int J Miner Process. 2000;58:145-66. https://doi.org/10.1016/ S0301-7516(99)00069-1.

Sikorskia D, Tabuteau H, Bruyn JR. Motion and shape of bubbles rising through a yield-stress fluid. J Nonnewton Fluid Mech. 2009;159:10-6. https://doi.org/10.1016/j.jnnfm.2008.11.011.

Wang RK, Liu JZ, Gao FY, et al. The slurrying properties of slurry fuels made of petroleum coke and petrochemical sludge. Fuel Process Technol. 2012;104:57-66. https://doi.org/10.1016/j. fuproc.2012.07.006.

Yianatos JB, Moys MH, Contreras F, et al. Froth recovery of industrial flotation cells. Miner Eng. 2008;21:817-25. https://doi. org/10.1016/j.mineng.2007.12.012.

Zhan XL, Zhou ZJ, Kang WZ, et al. Promoted slurryability of petroleum coke-water slurry by using black liquor as an additive. Fuel Process Technol. 2010;91:1256-60. https://doi.org/10.1016/ j.fuproc.2010.04.006.

Zhao L, Li AF, Chen K, et al. Development and evaluation of foaming agents for high salinity tolerance. J Pet Sci Eng. 2012;81:18-23. https://doi.org/10.1016/j.petrol.2011.11.006.

Zheng X, Franzidis JP, Manlapig E. Modelling of froth transportation in industrial flotation cells part I. Development of froth transportation models for attached particles. Miner Eng. 2004;17:981-8. https://doi.org/10.1016/j.mineng.2004.03.004. 